\title{
SOME ETIOLOGICAL FACTORS IN THE COELIAC SYNDROME*
}

\author{
BY
}

\author{
ALAN BROWN, M.D., F.R.C.P., F.R.C.P.(C) \\ Professor of Paediatrics, University of Toronto
}

Introduction

To speak to an audience at the University of Birmingham about the coeliac syndrome, a disease which has been encountered, studied, and treated more often here than probably anywhere else in the world, and where much fundamental research into the etiology, diagnosis, treatment, and understanding of this disease bas been carried on, is "like carrying coals to Newcastle'. I refer to the many papers produced by Sir Leonard Parsons, Doctors Neale, Hickmans, and Ross, and to Professor Frazer's recent work on fat metabolism.

As pointed out by Sir Leonard Parsons in his Rachford Memorial Lectures in 1931, there is little of importance known today that would alter Gee's original description of coeliac disease. It is interesting to note that most of the present-day researches are concerned with possible abnormalities or causative factors which were mentioned by the original writers on this subject. The absence of pathological findings was noted by Gee. A possible deficiency of bile salts was considered by Cheadle in 1903, but has since been disproven. Herter in 1908 felt that coeliac disease was caused by some infection. He also drew attention to the stunted growth, and the condition is sometimes known as 'Herter's infantilism'. Schütz in 1905 thought that abnormality of the secretory and absorptive functions of the intestine was a factor. A theory suggested by Moncrieff and Payne was that the disease was due to a metabolic error similar to that occurring in diabetes. The presence of excess fat in the stools was noted by Cheadle in 1903 and has been the subject of much investigation since.

It will be noted in the observations that I am about to make that many of these possible causes are discussed again in more recent studies of the disease.

We have confined the term coeliac disease to the condition of infancy and early childhood in which there is persistent diarrhoea with foul, undigested

- Being an Ingelby Lecture delivered before the University of Birmingham on May $20,1948$. stools which cannot be accounted for by a bacteriological or other cause. The subjects bave poor appetite, fail to gain weight properly, have a protuberant abdomen, and respond to high-protein feeding. The other signs and symptoms are too well known to be dwelt upon further. Cystic fibrosis of the pancreas has not been included.

The following case record will serve to illustrate some of the usual findings in the histories of patients with coeliac disease.

\section{Case Record}

V.D. This patient, a two year old girl, was first brought to the hospital with a history of an enlarged abdomen for several months. Three months before admission she became listless and irritable with loss of appetite. Two months before admission she had five or six watery, pale, yellow stools daily; these contained many large curds. At this time the patient had lost weight, and there was considerable gas in the bowel. There were no other known cases in the family, but a grandmother and an uncle had diabetes.

The child showed marked loss of weight and the abdomen was distended and tympanitic. An oral glucose tolerance test showed a flat curve, as did the vitamin A absorption test.

Treatment consisted of a high protein diet and intramuscular injections of crude liver extract and vitamin B complex daily for three weeks. As the stools improved and the child gained weight, vitamins $D$ and $C$, as well as the ferrous sulphate were added, and the child was able to go home.

One year later the child was re-admitted to the hospital following a recurrence of the condition, which had been treated in another city for three months. She was now three years old, and was found to be in an emaciated condition, weighing only fifteen pounds (fig. 1).

The condition improved after treatment with high protein diet, and in three months the picture had changed (fig. 2).

Bouts of indigestion returned with infections of the upper respiratory tract in the following two years, but she continued to grow and the digestive upsets became less severe. 
The Present Investigation

From 1932 to 1945 we had 150 children admitted to our institution with the diagnosis of coeliac disease. Ninety of these have been used for analysis in this report.

Fifty children suffering from so-called coeliac disease had a history of infection at the onset of their symptoms. The infection was either acute or chronic, and the following varieties were listed:

$\begin{array}{lr}\text { Tonsillitis } & 30 \\ \text { Otitis media } & 9 \\ \text { Nasopharyngitis } & 5 \\ \text { Acute bronchitis } & 4 \\ \text { Cystitis } & 1 \\ \text { 'Intestinal influenza } & 1\end{array}$

Many cases 'with an onset following tonsillitis relapsed during a recurrence of the tonsillar infection, and it is interesting to note that of twenty children who were re-admitted with a recurrence of the coeliac syndrome, eighteen showed a recurrence of the primary infection. Even after removal of tonsils and adenoids, the coeliac condition is apt to recur, but less frequently. Whether these relapses are due to the infection itself or to a generally weakened resistance, resulting from the infection, or to impaired absorption of vitamins, is still an open question. The incidence of cases with an onset associated with infection is higher, as one would expect, during the season when respiratory diseases are most common. The onset of signs and symptoms of coeliac disease occurred immediately after the infection in thirty-five of the fifty cases. Two of the children with recurrent infections had diarrhoea and vomiting from birth, until a more severe infection caused the fully developed disease. Eight cases developed gradually.

In another group, which may be called 'idiopathic coeliac disease', are the remaining cases, in which there is no proof of any underlying infection. Many of these cases had their onset in the summer months. Of the thirty-four children in this group, eighteen showed a gradual onset of the coeliac syndrome; three cases developed gradually after birth, two developed diarrhoea when the diet was changed, while in the remainder the exact time of onset could not be determined. It is thus evident that an infection is followed usually by a rapid onset of diarrhoea, vomiting, foul, bulky stools, and general irritability. In the idiopathic cases a tendency to a gradual appearance of signs and symptoms prevails, the most common complaint being stationary or decreasing weight, soon followed by laxity of the bowels and abdominal pain due to an accumulation of gas, probably a manifestation of lowered carbohydrate tolerance which in turn follows the initial steatorrhoea.

Approximately two-thirds of the children with coeliac disease were never breast-fed. It should be noted that in infants who had been breast-fed the disease appeared on the average at sixteen months of age, while in bottle-fed infants it appeared on the average at ten months. This suggests that breastfeeding has a preventive effect or is responsible for delaying the onset of the condition. Eighty-five per cent. of the cases so tested showed a low or flat curve in one or both of the glucose tolerance and vitamin $A$ absorption tests.

It was noted that about 50 per cent. of the children had not received vitamin $C$ or $D$ in the first six months of life. One must, however, view this fact with caution because we do not suppose that the absence of these vitamins is entirely the cause of coeliac disease.

The patients were brought back to the hospital for a follow-up examination in which a careful medical, dental, and genetic study was carried out. The results of this follow-up study have revealed some interesting findings.

Dr. Milner, working under Dr. Fisk, who is in charge of orthodontics in the hospital, has made the following preliminary report of the results of the dental examination of formal coeliac patients: generally speaking these children are "caries immune', and their saliva tests show 'caries immunity'; they have a neutero-occlusion molar relationship, a wide dental arch, more than usual spacing when the anterior deciduous teeth are shed, and a deep overbite.

Dr. Margaret Thompson, working under Dr. Norma Ford Walker and in co-operation with Dr. Ebbs, has conducted a careful genetical investigation of ninety former coeliac patients and their families, in order to determine if coeliac disease depends in any way for its expression upon hereditary factors. She has found that these children tend to appear late in the birth rate of the family, that the average age of their mother is older than normal, and that their dermal patterns suggest possible disturbance of growth in prenatal life. In this series there were more brothers, sisters, and relatives affected than would be expected, and diabetes was a hundred times more common amongst them, fifty times more common amongst their siblings, seven times more common in their parents, and twice as common in their grandparents than in the normal population.

It seems reasonable, from the above facts, to suggest that all coeliacs are potential diabetics. 'Congenital familial steatorrhoea' was the term given to cases described by Garrod and Hurtley in 1913 that had symptoms not unlike coeliac disease. The possible similarity to diabetes was suggested by Moncrieff and Payne (1928), two concluded that coeliac disease is a fault of malutilization of fat and not of malabsorption. McRae and Morris (1931), however, showed that there was faulty absorption of fat in patients suffering from coeliac disease, and Poynton and Cole have described a case of coeliac disease which developed diabetes mellitus.

The high incidence of digestive difficulties in the families of coeliacs led Hablutzel Weber (1923) to suggest a constitutional factor in the etiology. The 


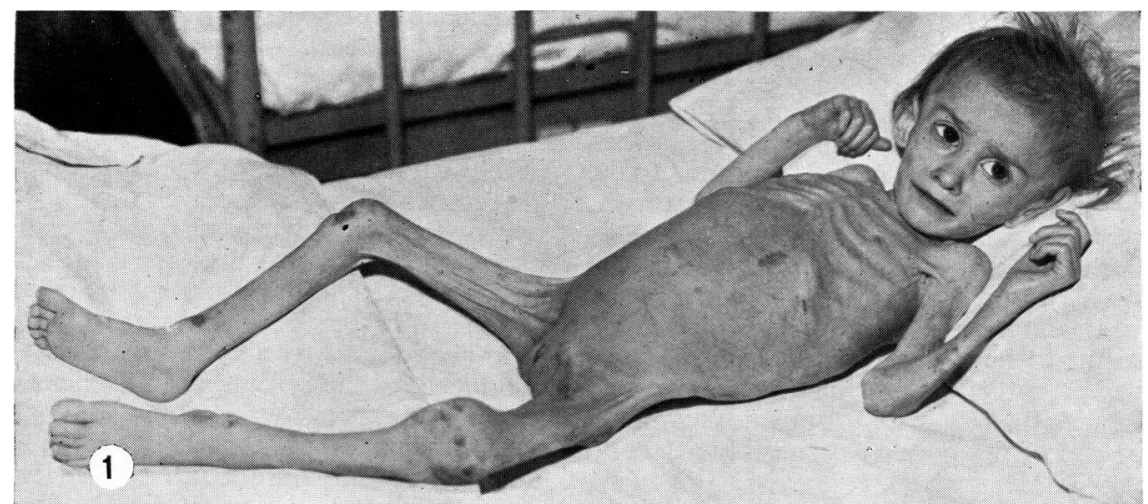

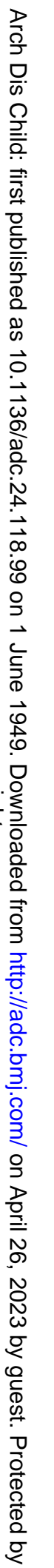

FIG. 1-Emaciated condition of V.D. (aged 3 years) on readmission.

FIG. 2-Front and side views of V.D. after three months' treatment. 
familial history was also referred to by Lehndorff and Mautner.

Stolte suggested the association of advanced age of the parents in some cases, and a long interval preceding the birth of the affected child. This latter is now considered to be an indication of reduced fertility.

It is also possible that we are dealing in coeliacs with an abnormal secretion of the pancreas, other than the external secretion which we consider to be normal. Another question has to be answered: Is there a general endocrine abnormality which is chiefly concerned with the pancreas? Recently Dragstedt and his co-workers have produced a factor from pancreas which they have called 'lipocaic', and which seems to have been effective in digesting fats-preventing fatty livers in depancreatized animals. Dragstedt felt that 'lipocaic' was an internal secretion of the pancreas, possibly a second hormone.

Let us go back now and consider one of the factors already brought out, that is infection. In 1925, Brown and his co-workers published the finding of a characteristic bacterial flora in the stools of coeliac patients, and dysentery was found in some cases.

\section{EXPERIMENTAL STUDIES}

Poisoning with iodo-acetic acid. Since the coeliac condition usually occurs in early infancy, and since among the principal contributing factors appear to be infection and improper feeding, we established the working theory that the coeliac syndrome might be produced in young albino rats by applying these two factors. Verzar and Laszt stated in 1936 that they were able to produce all the symptoms of coeliac syndrome in rats by poisoning them with iodo-acetic acid. Verzar found in his studies of intestinal absorption of carbohydrates that glucose and galactose were gradually absorbed; while this did not occur with other hexoses of the same molecular weight (mannose, sorbose, xylose, arabinose). These were absorbed in accordance with the law of diffusion, the former not. But the same quantity was always absorbed in a given time. Verzar postulated a special activity of the mucosa of the jejunum which is influenced by the $\mathrm{pH}$ of the intestinal contents. But this activity of the mucosa was inhibited by: (a) low temperature, and (b) iodo-acetic acid. It is known that iodo-acetic acid interferes with the oxidation-reduction processes connected with the resynthesis of hexose phosphoric acid during the recovery process of the muscle. If a similar transformation of glucose might occur in the cells of the intestinal mucosa, this process might be stopped by iodo-acetic acid. The constant transformation of glucose in the mucosa would maintain a high diffusion gradient between the sugar in the intestinal lumen and that in the mucosa by constantly transferring the sugar which is diffused into the mucosa cells and forms another substance.
Verzar and Laszt, studying the resorption of the fatty acids, found that glycero-phosphoric acid increased their resorption and believed that this phosphorylation process might also take place in the mucosa of the intestine. This phosphorylation process of the fatty acids was stopped by iodo-acetic acid as well as by phlorrhizin. The same inhibition of the resorption of fats took place after adrenalectomy. Wilbrandt and Lengyel studying the influence of the adrenal cortex, found that the phosphorylation process which was stopped following adrenalectomy was reversed after administration of adrenal cortex hormone, and Verzar and Laszt said that it had the same effect as riboflavin phosphate on the absorption of fats. The same authors state that poisoning with iodo-acetic acid in albino rats, when given orally, produced all the symptoms of the coeliac disease.

My colleagues, Ebbs and Stein, fed to rats the sodium salt of iodo-acetic acid with their diet. $0.1 \mathrm{mg}$. of the sodium salt of the iodo-acetic acid was mixed with the daily diet, which consisted of $10 \mathrm{~g}$. approximately, but they were not able (even in repeated experiments) to observe any abnormality in these animals. They increased in weight normally and the blood count was normal.

In the next series of experiments they increased the amount of iodo-acetic acid to $10 \mathrm{mg}$. in $10 \mathrm{~g}$. of diet. No effect was observed; the animals grew normally, and there was no sign of diarrhoea. They continued the experiments until the animals had reached the weight of full-grown rats and were unable to observe a single death as described by Verzar and Laszt, who regularly observed death within three weeks after the experiments had started. Even when $100 \mathrm{mg}$. of the sodium salt was given to $10 \mathrm{~g}$. of diet there was only a delayed increase of weight during the first week, but the rats showed a completely normal development after this period, so that they looked like the control rats, sometimes even surpassing them in weight.

Let us discuss the reasons why they were unable to get the results obtained by Verzar and Laszt. There is first the possibility that there might be some different factors active in our diet which were not present in the European diets. Some authors refer to the fact that sulphur-containing amino acids, which are found in some cereals, prevent the effect of iodo-acetic acid, and they propose a diet with a low protein content. Such a diet, indicated by Stevenson and White, was given and it was found that there was a stunting of growth, but merely because the animals did not like the food. Besides this, the diet lacked biotin and pantothenic acid, and after some fourteen days it was observed that all the symptoms of starvation and vitamin B deficiency developed. The same effect was produced without iodo-acetic acid, another proof that the diet was deficient.

The second possibility might be that the Wistar strain used for the experiments reacted in a different manner from the strain used by Verzar and Laszt, and therefore in a new series of experiments Yale 
rats were used which show a special tendency towards renal diabetes. But these rats also did not react, neither did hooded animals. In their publication Verzar and Laszt do not indicate the strain of rats they used.

The third possibility which may have played an important part in Verzar and Laszt's experiments is a chronic (more or less latent) infection in the animals they used. The coeliac-similar-syndrome they observed might have been an exacerbation of one of these infections. The most frequent infection met with in rats is bartonellosis. Martin Mayer was able to prove that this infection befalls practically every rat and is carried by the rat lice from one animal to another. Once an infection becomes active the animals die after one to two weeks, showing the symptoms of pernicious anaemia. The infection is always activated following splenectomy; the splenectomized animal succumbs within some days with the signs of pernicious anaemia. In experiments in which the blood of splenectomized rats was injected into young animals receiving iodo-active acid, an immediate stunting of growth was observed as long as the bartonella persisted in the blood. After about one week the bartonella disappeared again and the rats continued to grow in spite of feeding iodo-acetic acid. When a heavily infected strain of albino rats (not belonging to our own colony) was obtained, $10 \mathrm{mg}$. per $10 \mathrm{~g}$. of the sodium salt of iodo-acetic acid was added to the diet; a loss of weight occurred and the animals showed marked diarrhoea and progressive anaemia, surviving only when vitamin $\mathbf{B}$ complex was given. Iodo-acetic acid given orally activates the bartonella infection in the same way as other poisons do, and it might be said that the rats used by Verzar and Laszt were more heavily infected and less resistant. It is a known fact that wild grey rats are more heavily infected with bartonella than the albinos.

Infuence of infection. With these findings as a background, improper feeding and infection were then tried in a series of animals. Ebbs and Stein chose for this purpose young albino rats, twenty-one days old and with an average weight of $25 \mathrm{~g}$. These animals were fed on a normal diet to which was added 20 per cent. vegetable oil with a low melting point (Mazola oil). At the same time the amount of choline was elevated to the ratio of $5: 1,000$. These rats showed in the first two weeks a partial stunting of growth, but developed later to a normal weight; the only remarkable fact was that the skin showed a greasy appearance. The latter might have been caused by the animals sitting in the food trays. The stools (although no investigation of fat content was made) showed a normal gross appearance.

The problem of producing an infection was a difficult one because a type of infection had to be chosen that would not spread all over the colony and at the same time would not produce an acute and stormy disease in the individual rat. The idea was to produce a focus of infection and for this purpose a streptococcus culture which was mixed with agar agar was chosen. The idea was that the agar agar, after becoming solid, would become a focus from which the streptococcus would spread. But it was not possible to gauge the dosage and most of the animals died after some days, and so some other method of producing the desired effect had to be tried. The rat is well known as an animal which is highly resistant to infection and, therefore, it was decided to give large doses of streptococcus toxin $(0.5 \mathrm{ml}$. daily) by injection. Young rats of about $25 \mathrm{~g}$. in weight were fed on the above high-fat diet. These rats showed, during the first week, stunted growth, but began to gain weight during the second week and showed, later on, a constant increase in weight although this was not as rapid as the control animals.

There was slight anaemia in both groups, but besides this no abnormalities could be detected. This picture was, however, completely reversed when iodo-acetic acid in quantities of $100 \mathrm{mg}$. per $10 \mathrm{~g}$. was added to the high-fat diet. When in addition streptococcus toxin in the dosage described above was given hypodermically it resulted in a picture which resembled the coeliac syndrome in every way.

The radiographic appearances of three animals are shown in Fig. 3. The control rat (a littermate of the other two animals) was fed the highfat diet, while the other two got $100 \mathrm{mg}$. per g. of iodo-acetic acid in their diet and besides this daily injections of streptococcus toxin. The radiographs were taken when the rats were fiftythree days old and had received the treatment for thirty-seven days. The two smallest rats developed diarrhoea, steatorrhoea, and a distended abdomen eight days after the start of the experiment. The red blood count went down to $4,500,000$. On the radiograph the distended abdomen and the osteoporotic appearance of the long bones are clearly visible. The fat content of the stools went up to over 10 per cent. in this group of animals.

In another group of animals that were on the high-fat diet to which iodo-acetic acid was added, but that did not get injections of streptococcus toxin, it was noted that in spite of the rats being underweight and anaemic the fat content of the stools was not as high as in the animals who got the toxin injections, and the red blood cells did not show such a marked decrease. To be sure that the toxin by itself and not the preserving cresol solution played the important role, another group was controlled by injecting only the preserving solution, but these rats developed only the signs described in the group given high-fat diet plus iodo-acetic acid, that is, moderate anaemia and grossly retarded growth.

How can the effect of the iodo-acetic acid be explained? Why does it not produce in normal healthy rats the symptoms described by Verzar and Laszt ? Ebbs and Stein were not able to find any gross pathological changes in autopsies of the animals. The liver cells were also normal and 


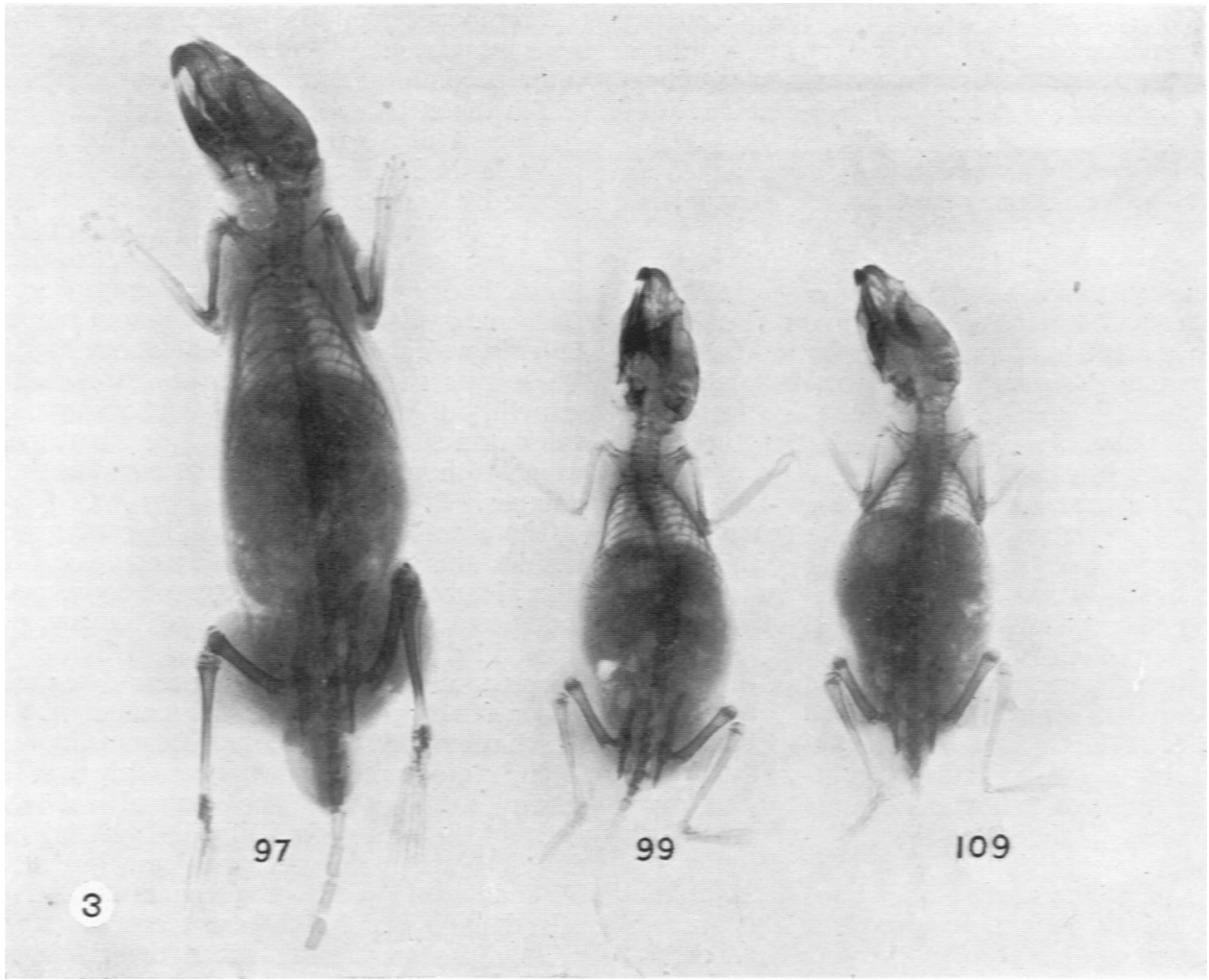

FIG. 3-Rat 97 is a control on high fat diet. Rats 99 and 109 show coeliac picture produced by giving $100 \mathrm{mg}$. per cent sodium iodoacetate and streptococcus toxin.

there were no fatty changes observed. Does the iodo-acetic acid or its sodium salt (which latter never does produce any irritating effect) activate latent bartonellosis? The explanation might be that the iodo-acetic acid has its effect only on animals whose resistance has deteriorated, and this fact might explain the production of the coeliacsimilar-syndrome in young rats whose resistance was lowered as a consequence of improper feeding and streptococcus injections.

Vitamin B complex. In a series of animal experiments for which about 450 rats were used an attempt was made to find out which factor of the vitamin B complex had some therapeutic effect on animals which presented the coeliac-like-condition.

ThIAMINe CHLORIDE. A group of animals fed on high-fat diet plus $100 \mathrm{mg}$. iodo-acetic acid to $10 \mathrm{~g}$. of diet, and who received every day streptococcus toxin hypodermically, developed the coeliac syndrome after about one week. When 10 gamma of thiamine chloride was added to the daily diet, there was no improvement. The animals showed stunted growth, steatorrhoea, and distended abdomen. Some died after about three weeks, and others continued to gain very slowly but always looked miserable.
After two months they were the weight of a normal animal of about three weeks. It has to be mentioned here that in all experiments the coeliacsimilar-condition could be produced only in those rats whose initial weight was not above $25 \mathrm{~g}$. Rats with the initial weight over $25 \mathrm{~g}$. showed a stunted growth for about a month, later developing a gradual increase of weight.

RiBoflavin, $3 \mathrm{mg}$. to $10 \mathrm{~g}$. of diet, gave no results. Some rats gained very slowly, but the majority did not recover.

RIBOFLAVIN PLUS THIAMINE CHLORIDE had no effect.

Nicotinamide was without any effect.

Riboflavin PHOSPHATE, 50 gamma hypodermically daily, had no effect; indeed the rats died almost earlier as compared with other groups and the diarrhoea was even more accentuated in these animals. (It might be possible that the acid as such acted as a poison.) Riboflavin phosphate fed with the diet (100 gamma daily) had no effect either. These experiments did not confirm Verzar and Laszt's postulations which claim that 'Flavinphosphoraeure' is the effective substance in the re-establishment of the impaired phosphorylation process caused by iodo-acetic acid poisoning. 
BREWER's YeAST. When $250 \mathrm{mg}$. Brewer's yeast was added to the diet containing $100 \mathrm{mg}$. of iodoacetic acid per $10 \mathrm{~g}$. and 20 per cent. of fat, plus streptococcus injections, there was an immediate gain of weight in the animals (Fig. 4). The fat content of the stools went down from 10 to about 7 per cent., and the red cell count increased from 4,500,000 to $6,500,000$ per c.mm. of blood in two weeks. One month after the introduction of Brewer's yeast the animals regained the weight and could not be distinguished from normal rats. How the effect produced by Brewer's yeast may be explained is difficult to say. When riboflavin phosphate is the

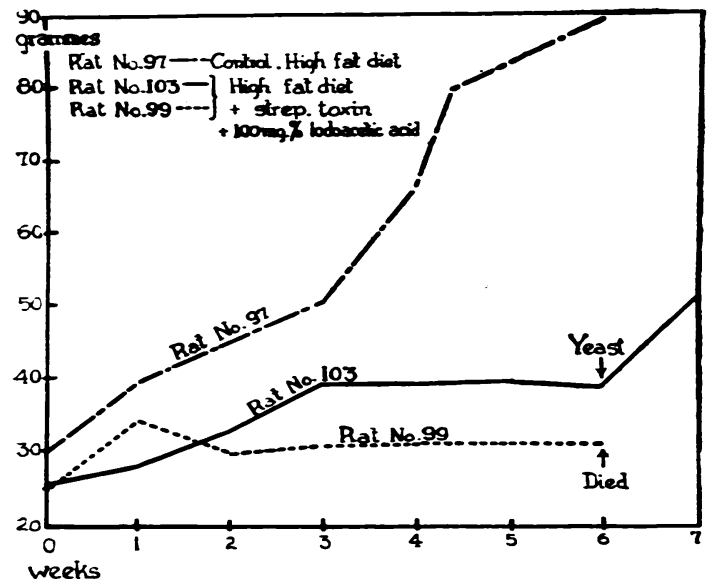

Fig. 4.

active substance, why does it not act in its pure form, but only within the vitamin B complex ? Are there other factors belonging to the vitamin $B$ group which are responsible for this activity? Should the effect of Brewer's yeast be based on the fact that the amino acids contained therein prevent the effect of the iodo-acetic acid ? To find an answer a control group was fed amino acids 'Amigen' in the same amount as Brewer's yeast, but this did not show any protective effect. The animals died within a few days while the controls fed Brewer's yeast survived and increased in weight.

Adremal cortex. A study of the effect of adrenal cortex hormone was carried out. To be sure of the poisonous effect of iodo-acetic acid, the sodium salt was injected every second day into a group of nine animals in doses of $0.1 \mathrm{mg}$. Five of them died within one week and the remaining four showed the typical symptoms described before. Some of these were given a daily dose of $0.5 \mathrm{ml}$. of adrenal cortex (15 dog units) hypodermically. The animals on adrenal cortex showed a slow increase in weight, the red cell count was $5,700,000$ per c.mm. of blood while the red cell count in the animal which did not receive adrenal cortex hormone was $4,700,000$. The fat content in the stools was 10.8 per cent. in the animal which did not receive adrenal cortex and 8.4 per cent. in the other animal.
Folic acid was given to a group of coeliac rats, but this had little or no effect upon the condition of the animals.

A question concerning these experiments is : Can the coeliac symptoms in albino rats, produced by the above-described methods, be prevented ? The answer is, if the rats are fed Brewer's yeast, they do not show any of the signs. When Brewer's yeast, $250 \mathrm{mg}$. daily, is given at the same time as the high-fat diet, the feeding of iodo-acetic acid, and/or the injection of streptococcus toxin, the rats develop normally and there is no sign of any of the coeliac changes.

Theories of the pathogenesis of coeliac disease. In 1932 Parsons' work in the Children's Hospital in Birmingham showed that although the faecal fat is not identical with the food fat, yet it depends upon the food fat and shows parallel variations. The theory that coeliac disease has an infectious origin has been worked upon by a number of investigators. In 1925 in our own clinic we found characteristic bacterial flora. In these cases it suggested a bacterial origin. Parsons investigated the bile in coeliac children and showed it to be similar to that in the normal child. In the important review by Parsons in 1932 he found that no one of the theories of etiology which were suggested could be considered adequate. He concluded that although up to the present no changes have been found in the intestinal secretion, the probable explanation of the coeliac disease lies in a change of physiochemical nature in the absorptive mechanism of the intestine. More recent studies lead to the same conchusion but the nature and cause of this physical, chemical change has yet to be determined.

As a result of numerous experiments in his Department, Frazer in 1947, in an interesting review of the 'Etiology of Steatorrhoea', has described the phases of fat absorption as divided into the intraluminar phase in which the fat is finally dispersed into a number of small particles, and the subsequent absorption through the cell wall lining the intestines. He has shown that fatty acids, monoglyceride, and bile salts must be present in order to get the maximum emulsification of the fat. This preparatory emulsification of the fat would be lost in conditions in which pancreatic enzymes were lost, that is in fibrocystic disease of the pancreas. He has suggested that fat is absorbed through the intestinal cells in the form of fatty acid or in small particles of fat, in which case the fatty acids reach the liver via the portal vein and the particles of fat reach the thoracic duct and then go into the blood stream.

Whether deficiency signs and symptoms in this condition are primary or secondary is still debatable. Peters in 1930 suggested that the B complex might be associated with fat metabolism. In 1942 May and his co-workers revived this view and thought that coeliac disease might be due to lack of specific food factor. They. produced evidence of clinical improvement in patients treated with crude liver 
extract. Folic acid therapy has been reported as giving help in some cases, but the results have not been uniform.

Gastro-intestinal allergy seems to have been associated in some cases of coeliac syndrome, and there are numerous reports suggesting this to be one of the causes. In 1938 in an important pathological investigation, Andersen separated coeliac disease from cystic fibrosis of the pancreas, on the basis of the presence or absence of pancreatic enzymes in the duodenal juice, and the presence or absence of the fibrotic changes of the pancreas at autopsy. Following this, May and his co-workers have done extensive work on faulty absorption in coeliacs and have pointed out that motility in the gastro-intestinal tract is reduced in coeliac disease. This impaired mechanical function, they claim, explains the defective absorption of carbohydrates. They also pointed out clumping of barium meal in the small intestine. The vitamin A absorption test was low in coeliac children, but tended to return to normal and the patient recovered. May, McCreary, and Blackfan in 1942, stated that it is now generally accepted that the basic fault in coeliac disease is defective absorption from the intestine, particularly fat and carbohydrate.

Andersen in 1947, in a discussion with relation to coeliac disease, points out that the lipase content of the duodenal juice is normal in the coeliac child, and according to her, this disease is an expression of a multiple deficiency state, when it is fully developed. This condition probably arises only in children with an underlying constitutional defect. Andersen pointed to the high familial incidence of the disease and to the incidence of starch intolerance in the siblings of coeliac children.

The majority of evidence to date points to a defect in the absorptive power of the intestine for fats and carbohydrates. The reason for this deficient absorption is still not known; infection, vitamin deficiency, allergy, constitutional factors, or a combination of any of these are all possibilities which have been put forward.

\section{Summary}

It must be apparent from the studies which we have made that very little has actually been added to our knowledge of this disease. However, our studies have served to emphasize again the fact that much of the knowledge of this disease, as recorded by the earliest writers on the subject, is being proven again. Particularly one is impressed by the presence of infection at the onset of this disease and by improper feeding durirg infancy and childhood.

The preliminary results of the dental survey indicate that the well-known clinical observation that children who have suffered from coeliac disease and have had proper dietary control are blessed with better than average teeth, is probably true.

The genetic investigation has thrown some light on the probable relation of coeliac disease to diabetes, and a possible pancreatic dysfunction of some type.

In experimental studies with animals the factor of infection has been emphasized and would appear to be a very important one.

The relation of vitamin B complex to the prevention and relief of the coeliac syndrome deserves further investigation.

Finally the cause of this condition can apparently be solved only by continued, co-operative effort in numerous branches of medical science.

\section{REFERENCES}

Andersen, D. H. (1938). Amer. J. Dis. Child., 56, 344-99. (1947). J. Pediat., 30, 564-82.

Brown, A.. et al (1925). Amer. J. Dis. Child., 30, 603-31. Cheadle, W. B. (1903). Lancet, 1, 1497.

Ebbs, J. H., Stein, W., and Marriott, M. Unpublished. Frazer, A. C. (1947). Brit. med. J., 2, 641.

Gee, S. (1888). St. Bart's. Hosp. Report, 24, 17-21.

Hablützel-Weber, E. (1923). 'Uber Intestinalen Infatilismus und das Schicksal der Träger desselben'. Leemann and Co. Zurich.

Herter, C. A. (1908). 'On Infantilism from Chronic Intestinal Infection, Characterized by the Over Growth and Persistence of Flora of the Nursling period: A study of the Clinical Course, Bacteriology, Chemistry, and Therapeutics of Arrested Development in Infancy'. The Macmillan Co. New York.

May, C. D., et al. (1942). J. Pediat., 21, 289.

Macrae, O., and Morris, N. (1931). Arch. Dis. Child., 6, 75-96.

Milner, E. Unpublished.

Moncrieff, A., and Payne, W. W. (1928). Arch. Dis. Child., 3, 257.

Parsons, L. G. (1932). Amer. J. Dis. Child., 43, 1293.

Peters, R. A. (1930). J. State Med., 38, 63-87.

Poynton, F. J., and Cole, L. B. (1925). Brit. J. Child. Dis., 22, 30-35.

Schütz, R. E. (1905). Jahr. f. Kinderh., 62, 794-807.

Thompson, Margaret. Unpublished.

Verzar, F., and Laszt, L. (1935). Pflüg. Arch. ges. Physiol., 236, 693.

(1936). Ibid., 237, 483. 